\title{
A ECA/USP e a Educomunicação: a consolidação de um conceito, em dezoito anos de trabalho
}

Ismar de Oliveira Soares

Professor livre-docente do Departamento de Comunicações e Artes da ECA/USP.

Jornalista responsável pela revista Comunicação \& Educação, coordenador do $\mathrm{NCE}^{1}$ - Núcleo de Comunicação e Educação,

e presidente da UCIP - Union Catholique Internationale de la Presse (2001-2004).

E-mail: ismarolive@yahoo.com

Em 1989, o Departamento de Comunicações e Artes da Escola de Comunicações e Artes da Universidade de São Paulo (CCA-ECA/USP) iniciava sua trajetória de pesquisas, publicações, ensino e extensão cultural na interface entre comunicação e educação. Inaugurava-se, naquele ano, o I Curso de Especialização em Comunicação e Educação (300 horas), envolvendo, praticamente, todos os docentes do departamento, aos quais se somaram professores da Escola e da própria Faculdade de Educação. O curso teve duas edições, formando, até 1991, um total de 80 especialistas.

Em 1993, um grupo do mesmo departamento, associando-se a um esforço latino-americano em torno de um projeto de formação superior que levasse em conta o fenômeno comunicativo a serviço da sociedade civil e não apenas da denominada indústria cultural, decidiu criar o Curso de Gestão de Processos Comunicacionais, levando o tema da inter-relação comunicação/educação para a grade curricular da nova proposta de pós-graduação lato sensu. No ano seguinte, o curso de Gestão colocou em circulação a revista Comunicação \& Educação, numa parceria com a Editora Moderna.

Em novembro de 1996, era constituído o Núcleo de Comunicação e Educação (NCE), vinculado ao CCA-ECA/USP e voltado tanto para a pesquisa quanto para a extensão cultural. Entre 1997 e 1999, o NCE promoveu, com uma amostragem formada por 176 especialistas de 12 países da América Latina, uma investigação sobre a natureza da inter-relação comunicação/educação e detectou, ao final, fortes indícios que apontavam para a emergência de um

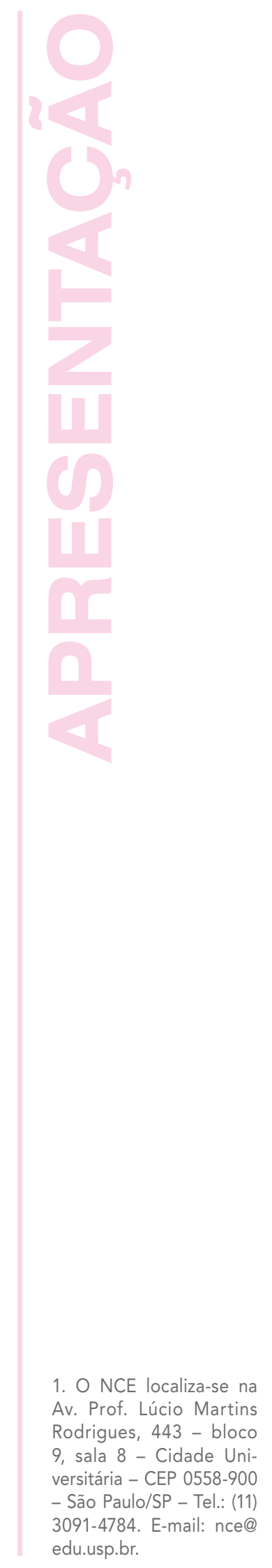


comunicação \& educação • Ano XII • Número 2 • maio/ago 2007

novo campo - interdisciplinar e autônomo - de intervenção social, então denominado educomunicação. Tal conceito anteriormente fora usado para designar tão-somente uma das áreas do novo campo, o da educação para a recepção ativa dos meios massivos. Em 1998, o mesmo Núcleo promoveu, em São Paulo (numa parceria com o SESC-SP, o Itaú Cultural e o Colégio Rio Branco), o I Congresso Internacional sobre Comunicação e Educação, trazendo ao Brasil 160 especialistas de 30 países. Pela primeira vez, o conceito da educomunicação era apresentado e discutido fora dos muros da Universidade.

Entre 2001 e 2006, o Núcleo de Comunicação e Educação do CCA foi chamado a prestar serviços de assessoria no campo da educomunicação para projetos nos âmbitos federal (Ministérios da Educação, Meio Ambiente e Trabalho), estadual (Secretarias de Educação de SP, MT, GO e MS) e municipal (Prefeitura de São Paulo e Prefeitura de São José dos Campos, através da FUNDHAS - Fundação Helio Augusto de Sousa), bem como no âmbito das empresas privadas (como foi o caso do Colégio São Luis, em São Paulo). Ao todo, foram formados mais de 20 mil especialistas vinculados a mais de 1.500 escolas, parte deles através de processos de educação a distância. O impacto de tais projetos acabou gerando políticas públicas de educomunicação, como ocorreu com a aprovação da Lei Educom, em dezembro de 2004, pela Câmara Municipal de São Paulo, que estabeleceu as modalidades do emprego do conceito por parte de Secretarias como as da Cultura, Saúde, Esporte, Meio Ambiente e Educação.

No mesmo período, um total aproximado de 60 pesquisas de mestrado e doutorado voltavam-se, somente no programa de pós-graduação da ECA/USP, para o novo campo. No momento, o Educom.rádio, realizado em 455 escolas de São Paulo, está sendo objeto de seis pesquisas acadêmicas, abordando cada uma um aspecto diferente da proposta que envolveu mais de 9 mil pessoas em meio a professores e alunos, entre 2001 e 2004.

Em 2006, o NCE deu início a uma parceria com o Jornal da Tarde, do Grupo Estado, para a publicação de uma página semanal, aos domingos ("Pais \& Mestres"), levando a prática educomunicativa para a sala de aula. Um ano depois de instalado, o projeto recebeu dois prêmios, um internacional e outro nacional, pelo ineditismo de sua proposta.

Finalmente, em maio de 2007, depois de dezoito anos de trabalho intenso e ininterrupto, o CCA encaminhou, para análise das autoridades da USP, um projeto inédito: a Licenciatura em Educomunicação. É a universidade reconhecendo e legitimando um movimento que nasceu fora de seus círculos, no coração da sociedade civil, ao longo dos últimos cinqüenta anos!

Tal trajetória foi acompanhada pela revista Comunicação \& Educação nos últimos doze anos, a qual vem contribuindo com seriedade e persistência ao abrir suas páginas tanto para pesquisadores e atores sociais da comunicação quanto para professores, em seu esforço de compreender a comunicação e levar suas tecnologias, linguagens e formas de gestão para o interior dos espaços e processos educativos. 


\section{ARTIGOS NACIONAIS}

Os artigos nacionais da presente edição voltam-se para as teorias e as práticas da recepção (Nilda Jacks e Daiane Boelhouwer Menezes), o ensino da comunicação (José Luiz Braga), o uso pedagógico dos processos comunicativos (Tânia Márcia Cezar Hoff) e, finalmente, para as linguagens da comunicação (Marly C. B. Vidal e Jane A. Marques).

Jacks e Menezes abordam o tema da Recepção de telenovela na década de 1990, apresentando o estado da arte das pesquisas de recepção de telenovela realizadas no Brasil, na década de 1990. Braga volta-se para o tema do ensino e pesquisa em comunicação, analisando a conhecida disjunção entre teorias e práticas na organização das formações em comunicação. Defende a proposta de se implementar uma composição não-disjuntiva entre contextos (sociais e de processos midiáticos) e formação profissional, envolvendo práticas e desenvolvimentos teóricos. Hoff reconhece a força do texto publicitário e o identifica com o suporte pedagógico. $\mathrm{O}$ artigo apresenta uma discussão de caráter teórico - e não prescritivo - a respeito da utilização do texto publicitário como suporte pedagógico na construção de um sujeito crítico. Finalmente, Vidal e Marques, ao analisarem a microssérie Hoje é dia de Maria, levam os leitores às histórias populares entremeadas de fantástico e recriadas a partir da oralidade. As autoras, referendadas pela teoria bakhtiniana, buscam compreender a relação entre a cultura popular e a trama ficcional televisiva.

\section{ARTIGO INTERNACIONAL}

$\mathrm{O}$ artigo internacional traz o texto de Isabel Ferin. Seu tema são os imigrantes e as minorias étnicas em Portugal, analisados a partir das representações produzidas pelos meios de comunicação. Nesse artigo, Ferin leva em consideração os fatores da globalização e o contexto europeu, evidenciando o papel da imprensa e, sobretudo, da televisão portuguesa na criação de estereótipos sobre as comunidades imigrantes.

\section{GESTÃO DA COMUNICAÇÃO}

A seção apresenta um artigo de Ana Paula Aleixo de Moura e Souza sobre a comunicação como mediação nos museus de arte. O trabalho tem por objetivo, a partir de um estudo ligado ao Museu de Arte de São Paulo, propor estratégias de atuação para que os museus possam legitimar-se como espaços de cultura e de memória na atualidade, considerando os processos comunicacionais que aí se constituem.

\section{ENTREVISTA}

A editora da revista Comunicação \& Educação, Cristina Costa, e a editora executiva Consuelo Ivo entrevistam Carlos Império Hamburger, o Cao, anali- 
comunicação \& educação • Ano XII • Número 2 • maio/ago 2007

sando, com o cineasta, seu segundo longa-metragem, o aclamado $O$ ano em que meus pais saíram de férias. O também diretor de Castelo Rá-tim-bum, O Filme e da série para o público infantil que deu origem ao filme, vencedora de prêmios em todo o mundo, fala da sua relação com o cinema e a televisão, e sobre as saídas possíveis para uma audiência mais crítica nas salas de aula.

\section{CRÍTICA}

A seção traz os resultados de uma pesquisa de Maria Aparecida Baccega e Denise de Oliveira Freire sobre a publicidade nos livros didáticos do Ensino Médio. A crítica, resultante de uma pesquisa acadêmica, procura verificar como a publicidade se apresenta no campo da comunicação/educação, especificamente do ponto de vista de sua inserção na educação formal. Para tanto, foram tomados os anúncios publicitários inseridos nos livros didáticos de Português para o Ensino Médio. Através de uma análise primeiramente quantitativa e, posteriormente, qualitativa, as autoras verificaram os modos recorrentes de exploração dos anúncios publicitários no processo ensino/aprendizagem.

\section{DEPOIMENTO}

A seção traz Renata Pallottini em Que sabemos nós de nós mesmos? Nesse depoimento, a dramaturga, contista, romancista, roteirista de telenovelas e séries para a TV, ganhadora dos mais importantes prêmios, como o Governador do Estado, Molière, Jabuti e Cecília Meireles, entre outros, narra como se interessou por teatro e como se aproximou da Escola de Arte Dramática da ECA-USP, nos anos 1970. Comenta que nesse período da vida política do Brasil teve início um verdadeiro concerto de condenações às suas peças, a começar por Enquanto se vai morrer..., uma apaixonada defesa do direito de amar e uma igualmente apaixonada acusação à pena de morte e ao castigo da tortura. Lembra que o texto ficou trinta anos engavetado, até sair do silêncio em 2002. Renata Pallottini reproduz nesse seu depoimento alguns trechos dos textos da Censura Federal, aos quais teve acesso recentemente.

\section{EXPERIÊNCIA}

Mayra Rodrigues Gomes relata a experiência pedagógica representada pela ferramenta wiki. Trata-se da descrição de como o wiki foi usado para trabalho de produção textual em disciplina de conteúdo teórico. Tal uso teve sua inspiração na possibilidade de trabalho com um processador de texto configurado para interação e construção hipertextual.

\section{POESIA}

Nos dois últimos números da Comunicação \& Educação, Adilson Citelli, editor da C \& E, dedicou-se a mostrar como se desdobram, nos textos poéticos, 
determinados processos de apropriação intertextuais e interdiscursivos. Falou, então, das recorrências entre Eduardo Alves da Costa, Martin Niemöller e Bertold Brecht. Nesta edição, o autor volta-se expressamente para Bertold Brecht, analisando seu conceito de comunicação, poesia e revolução.

\section{SERVIÇOS}

Monica Kondziolková apresenta o Instituto Arte na Escola (www.artenaescola. org.br), organização do Terceiro Setor responsável pelo Projeto Arte na Escola, criado em 1989 pela Fundação Iochpe. Comenta que o projeto desenvolve parcerias com 55 Pólos Universitários, estando presente em 48 cidades de 24 Estados brasileiros. Explica como a Rede Arte na Escola, com seus 413 parceiros (instituições educacionais e culturais, públicas e privadas), dissemina e multiplica ações de educação continuada para professores da rede pública de ensino em todo o País, além de distribuir materiais educativos de apoio ao professor.

\section{VIDEOGRAFIA}

Maria Ignês Carlos Magno analisa os filmes Zuzu Angel (2006) e Lamarca (1994) como um exercício da descoberta do que historicamente não foi dado a ver e da percepção das inter-relações existentes entre informações, memória, documentos, pesquisa histórica, linguagens, pontos de vistas, ficções. Seu objetivo é mostrar as conexões entre saberes tomando a poesia como o fio condutor da leitura das cinebiografias propostas (Sérgio Rezende. Zuzu Angel. Chico Buarque de Hollanda. Lamarca. Charles Dickens. Saberes interligados na narrativa cinematográfica).

\section{BOLETIM BIBLIOGRÁFICO}

As subseções Bibliografia sobre telenovela brasileira e Bibliografia sobre comunicação e educação trazem livros, teses e dissertações sobre as respectivas temáticas. Endereços úteis na internet pode contribuir para incrementar as tarefas cotidianas dos professores.

\section{ATIVIDADES EM SALA DE AULA}

Ruth Ribas Itacarambi propõe projetos pedagógicos a serem desenvolvidos em sala de aula com alunos dos Ensinos Fundamental e Médio, utilizando-se dos artigos publicados neste número. As três atividades têm como propósito apresentar sugestões para discutir as novas formas de ensino e aprendizagem, promovendo a interação entre as diferentes áreas do conhecimento na perspectiva da sociedade atual. 
comunicação \& educação • Ano XII • Número 2 • maio/ago 2007

\section{CONCLUSÃO}

Esta edição da revista Comunicação \& Educação, unindo-se ao conjunto dos esforços do CCA-ECA/USP no campo da Comunicação/Educação, mantém a tradição de abordar, em suas distintas sessões, as diferentes áreas da educomunicação, quais sejam, os "estudos da recepção e a educação para a comunicação", a "mediação tecnológica nos espaços educativos", a "expressão comunicativa através das artes", o "uso educativo das linguagens da comunicação", a "gestão da comunicação em espaços educativos" e, especialmente, a "pesquisa”, como reflexão epistemológica sobre a interface comunicação, cultura, tecnologias da informação e educação.

Resumo: A trajetória de dezoito anos de pesquisas, publicações, ensino e extensão cultural na interface entre comunicação e educação do Departamento de Comunicações e Artes da Escola de Comunicações e Artes da Universidade de São Paulo (CCAECA/USP), a partir de 1989, é relembrada nesta apresentação para anunciar que o CCA acaba de encaminhar, para análise das autoridades da USP, um projeto inédito: a Licenciatura em Educomunicação. Uma trajetória que a revista Comunicação \& Educação acompanhou nos últimos doze anos, abrindo suas páginas tanto para pesquisadores e atores sociais da comunicação quanto para professores, em seu esforço de compreender a comunicação e levar suas tecnologias, linguagens e formas de gestão para o interior dos espaços e processos educativos.

Palavras-chave: educação, comunicação, educomunicação, pós-graduação, extensão.
Abstract: The pathways of eighteen years of research, publications, teaching and extension programs in the interface between communication and education in the Departamento de Comunicações e Artes of Escola de Comunicações e Artes of Universidade de São Paulo (CCA-ECA/USP) are remembered in this introduction to announce that CCA has just sent, for USP authorities analysis, a brand new project: Educommunication Teaching. The journal Comunicação \& Educação has followed that trajectory for last twelve years, opening its pages to researchers, educommunication social actors and teachers in their effort to understand communication and take its technologies, languages and management ways to the inside of educative spaces and processes.

Keywords: education, communication, educommunication, postgraduate education, extension programs. 